\title{
Analysing the Gap Between the Existing And Expected Management Information System in Educational Institutions
}

\author{
Rubina Ashmi ${ }^{*}$,Ravichandran ${ }^{\dagger}$ \\ ${ }^{*}$ Madurai Kamaraj University,India
}

\begin{abstract}
With the advent of major changes in the education systems of the country and the technology nvolved in managing higher educational institutions, a critical study on the management information systems in higher educational institutions like colleges has become important and hence the need for this study has risen. In the 1960's and 1970's, there were new studies that tried to reform the educational systems in order to change the social and economic concepts ${ }^{l}$.Management Information System has undergone many changes from the techno-centric type to a better-balanced technology in terms of social, management and organizational focus.
\end{abstract}

Keywords: E-Management Information System, Academic Institutions Management System, Management Information System, International Institute of Educational Planning, Decision Support System

\section{Introduction}

The Management Information Systems helps in introducing new set of strategies in order to improvise the information strength of the organization. From the early days, the use of information technology was based on the attitudes of users and how information technology was accepted. Vast studies were conducted in the field of Management Information System based on the research methods, theories and topics.

An Education Management Information System is actually a decision making tool that is used to perform all the activities of an educational institution. According to Hua and Herstein (2003) such activities include checking, estimating, financial plan, development and data analysis at all stages of an education institution.

An Educational Management Information System (E-Management Information System)is necessary for the process of automation of the information at the educational institution. The main aim of creating such a system is "to provide Right Information to Right People at Right Time for decision making and controlling" Web technology is considered as a primary source for the colleges. Hemmi, Bayne and Land (2009) stated that web technologies are very essential for the higher education institutions as these technologies have the capability to both limit and extend the effects that they can have on the education institutions.

By introducing a Management Information System to a higher educational institution the following advantages are observed

- The day to day activities like student data, attendance, accounts, etc., are handled in a more organised manner

- Any job that would double up the time and effort can be simplified and done in no time; this means that the need for labour could be reduced to a large extent.

- The overall management efficiency can be improved

The educational institutions will have to transform the data being collected into information, so that every stakeholder who is being linked with the institution can feel the transparency of the system. Such transparency will in turn result in good educational channel for the students. Therefore it is very important to understand the use of data in order to improve the institutional standard. It is also important to analyse the education programmes before implementing them into action so that the overall efficiency of the institution can be sustained on a long- term basis.

In general, there are three types of challenges faced by the information system relating to the key management issues. They are

* The strategic business challenge-this challenge is mainly related to how the business can use information technology in order to become aggressive, efficient and digitally enabled

* The globalization challenge-this challenge is related to the fact that how the companies can understand the requirements of the system and business in this globally challenging market.

* The information architecture and infrastructure challenge-this challenge is mainly concerned with the process of developing the information architecture and information technology infrastructure which can assist in adapting to fast changing business conditions and technologies. 
It is not a very simple task to create, manage and maintain the Management Information System for a higher educational institution. Hence the same will have so many issues and challenges that must be faced by the institution.

The following are some of the challenges that are being faced in such a scenario.

a) An educational institution will have to consume a large amount of space to process the data and the Management Information System must generate a lot of operational information.

b) The very large amount of data body must be managed. This body of data is called as the 'content' of the organization. The content analysis is usually done in order to learn the alternating and improving trends and changes in the Management Information System, which would also help in finding the common elements and to compare the productivity of the organization. Also technological advancements in the Management Information System help in the improvement in the business and marketing implementations of the institution.

c) The research data also proposes a big challenge to the higher educational institutions.

d) Technology - The information system at the college must be updated to meet the demands of the existing updated technology. The technological advancements in the management information systems of the colleges help in the rapid developments of the success of the institutions.

e) Financial Resources-the budget for the making the Management Information System for the colleges must be sufficient

f) Transparency-The main challenge is to maintain the transparency in managing the information system between all the departments and employees at all levels.

g) Co-ordination- There must be a proper co-ordination of information and usage of information within and outside the colleges

h) Attitude of the management- The management must promote an open system so that everyone who is connected to the college can feel the transparency of the Management Information System.

i) Dynamism of the environment-The Management Information Systemfor the colleges are supposed to be in a complex nature and it is very much necessary for the management to have a proper virtual knowledge and change management concepts.

Studies reveal that there is not much awareness about the Information Security in the higher education institutions of the developed countries. It is very important to maintain the information security of the college management information system. Such a concern was expressed as early as 1975.Especially in the United States, there are Information Technology experts who insist that the universities and college representatives must be ensuring the security of the computer networks and information of their institution. The open network architecture is increasing the risk of information security. Denning (1999) states that there must be enough training and education in order the secure the information of the institution.

Diffenbach (1988) did a system test to select the candidates for the college in the admission process.Iyengar(1997) invented a system for the admissions for the Masters in Business Administration program.

\section{Background}

The history of Education Management Information Systems (E-Management Information System) dates back to the 80 's.During that time, many countries where coming up with the projects of taking annual census for the schools and maintaining the operations of the administrative issues.

There are vast literatures existing on the Management Information Systems in different countries. Gulsim Kadyrovna Sagitova studied about the process of automating the Management Information System in the Kazakhstan educational institutions. This study mainly concentrated on three aspects of Management Information System.

(a) The functional scheme

(b) Decomposition of a Management Information System

(c) Functional complexes

Every activity of an educational institution falls under one of the following three categories

1. Training activities

2. Educational activities

3. Management activities

The proper focus and utilization from all these three activities are responsible for improving the quality of the institution and to develop better futuristic opportunities. 
D.K.Allen and T.D.Wilson studied about the Management Information System in UK higher educational institutions. According to their study, the heads of the departments must keep the academic leadership focused in the path for success, also the study revealed the major elements that must be adopted into the higher educational institution. The elements are including four types of staffs namely the research staff, teaching staff, management and administrative support staff and the staff of academic support services.

The International Institute of Educational Planning (2010) notified the proofs that showed a good plan for an education system. This plan was supposed to have consisting of very clear goals, vision and Management Information System statements of good quality, ideas to expand the institution in order to improve the facilities. Therefore having such plans will aid in the proper utilisation of the resources by the educational institution.

Green (1994) empathised the importance of having the proper Management Information System for the higher educational institution. When the institution has a proper Management Information System and vision, the goals can be achieved very easily.

Batten and Trafford (1985) mentioned in their article about the importance of quality in an educational institution. They said that quality is a more dynamic aspect.

Supporting the concept of dynamicity, Findlay (1998), Levine (1982), Ross \& Mahlck (1996) stated that in order to maintain and improve the quality of higher education, change is very essential for growth and this change must be adapted at a very steady and measured level.

Quality of the educational institution depends on four main aspects. They are

$>$ The goals, including the Management Information Systems and purpose of the educational institution.

$>$ The steps for achieving the goals of the institution.

$>$ The result obtained from the goals that are being adapted.

$>$ The level up to which the set goals are being achieved.

The Decision Support System is very much helpful in generating the timetables for the classes for the universities and colleges. The process of course scheduling helps in generating the timetables for the respective hour for the respective teachers in the respective classrooms. In the year 1989,Chantal and De Werra developed a system to ease the class scheduling process. This system aimed to sort out the confusions that could possibly be caused in the process of scheduling the classes. Yet another tool for the decision support system is called as the slot manager. This slot manager adopts a method, which was originally designed by Liang et al. This had three main components namely interfaces, databases and an optimization model.

A Management Information System must be an integrated system, which can effectively make use of all the information resources that are actively linking all the departments of an educational institution. Simons model of decision-making has three phases. They are intelligence, design, choice and implementation. Intelligence is required to observe the objectives and to recognise the problems of the organization. The data must be collected and transformed into information. The design phase is used to create the alternatives for the measures that must be adopted by the organization. While talking about the design of the Management Information System, there are various factors that influence it. They are

$>$ Defining the problem

$>$ Setting the objectives of the system

$>$ Drawing the internal and external constraints

$>$ Fulfilling the information needs

$>$ Knowing the information sources

$>$ Analysing the available alternatives

$>$ Finalising the design report

The choice phase is used to make the right choice in order to evaluate the choices and choose the right choice. The implementation phase is used to implement the chosen choice with a confirmed decision based on which the overall system could be made effective.

The implementation phase is supposed to have a plan according to Dr.V.D.Dudeja (2000). This plan must include

1. Making the organizational plan

2. Planning the work flow of the organization

3. Training the workforce

4. Developing the software

5. Installing the systems

6. Designing the forms for data-collection

7. Building the data file

8. Operation of the system 
9. Upgrading the style of the system

10. Maintenance and development

Maintenance can be done at the following stages at the respective activities

* Making changes to the policy statements

* Generating reports

* Creating forms

- Operating systems

* Hardware

* Making changes to the software

* Controlling the system and developing the security models

* Creating inputs from the environment

There are six stages of implementation in the Management Information System

1. Hardware(install, test)

2. Software(install, test)

3. Data(enter, verify)

4. Procedures(document,test,people,train,hire)

5. Test

6. Implement

D.P.Goyal (2001) has proposed certain attributes, which are necessary while constructing a model of Management Information System. These attributes are as follows

1) Timeliness

2) Relevance

3) Accuracy

4) Completeness

5) Adequacy

6) Explicitness

7) Exception-based

The Bologna declaration (1999) by the European Ministers of Higher Education, argued that the constant performance evaluation of the educational institution would help in quality assurance. These days the educational institutions all over the world are to trying to improve the performance and assure better quality.

In the field of Management Information System, it is important to evaluate both the organization and the individuals. This needs to be done in order to know how much the users have related to and known the technology.

According to Nur Naha Abu Mansor, a performance management system must have the following five characteristics

1. The performance of every employee must be synced with the objectives of the organization

2. A thorough understanding of the work culture of the organization

3. Clarity in the requirements and specifications in order to meet the desired result

4. The transparency in the management in order to promote flexibility

5. Collecting and storing the reports of progress, so that the employees can monitor the performance management at work

A good model for quality assessment must have a two-stage approach. The first stage is the internal self-evaluation and the second stage is an external peer-review. Once the data is being collected about the tutors. The Bayesian network is the tool that could be used to organize and analyse the collected data, so that the future prospects of the tutors can be interpreted with regard to the institution.Main Thrust of the Paper

Academic Institutions Management System in general has two operating bodies. They are Intrinsic and Extrinsic bodies. The intrinsic bodies includes the following

1.Management

2.Students

3.Employees (Teaching and non-teaching)

4.Parents 
And the extrinsic bodies includes the following

1.Government

2.Media

3. Society

The objectives that are set to determine through this study are as follows

$>$ To critically examine the significance of Management Information System in Higher Education Institutions.

$>$ To study and analyse the existing Information System in the Educational Institutions in general

$>$ To examine the challenges related to the management of information in colleges.

$>$ To study and analyse the use and impact of Information Technology in colleges.

$>$ To develop an appropriate model of Management Information Systems for colleges.

$>$ To provide suggestions for the effective development and functioning of Management Information Systems in colleges.

$>$ To study the impact of technology in higher educational information systems.

In general, a Management Information System must have the following five characteristics.

* Standardisation

* Accessibility

* Flexibility

* Maintainability

* Protection

\section{Future Trends}

In future the educational institutions must have computerized dealing with the overall management. An ideal Management Information System for an educational management information system must have the following criteria's

- Admission

- Budget

- Fees Management

- Class schedules/Examination schedules

- Academic Calendar

- Attendance records

- Staff details - Academic and Non Academic

- Student details

- Alumni

- Library

- Validated user login- Staff, Students, Parents

- Course structure and syllabi

- Examination details

- Online fees management

- Display of academic calendar

- Display of examination result/Internal marks

In future an educational system will be considerably good if they adopt the following

1.The institutions must have user id's and passwords for students, staff and parents

2.The college website must cover the attributes including the information about institution, administration, courses offered, course structure, examination and alumni.

3.The information system of the educational institution must have an automated Admission Management System, Human Resources Management System, Academic Planning and Execution System, Student Service Portal, Information Resource Center, Accounts Management System, Library Management System, Alumni Information System,

\section{Conclusion}

An Educational Institution is efficient when it is computerised to the extent that the people at all levels of management must have a transparent access to all the information about the institution. If an educational management information system is capable of reducing the need for the presence of humans for the operation of the systems, that would be a considerable success in achieving the objective of this paper. There must be enough 
funds available to develop and maintain the information system of the institutions. The capabilities to process the information must be efficient.

\section{Acknowledgement}

I deem it as a privilege to thank my research guide Dr.K.Ravichandran, Professor \& Head, Madurai Kamaraj University, for his insightful and inspirational guidance. His willingness to exceed help at any time of the day enabled me to complete this work.

I am grateful to my mother Mrs.Ashaliand my daughter Azawho supported me through the entire research process.

I owe my thanks to my teachers, friends and well- wishers who helped me at various levels by providing valuable insights to the research work.

I place on record my gratitude to the respondents who readily responded to my study.

I thank God Almighty for all the blessings, grace and mercies He has showered on me and for lending me successfully through the various stages of this work.

\section{References}

[1]. Brickman, W., 1973. Comparative Education: Concept, Research and Application.Norwood Editions, Norwood (Pennsylvania).

[2]. Baskerville, R. L., \& Myers, M. D. (2002). Information systems as a reference discipline.MIS Quarterly,26(1), 1-14.

[3]. Andrzej Sobczak, Daniel M. Berry,'Distributed priority ranking of strategic preliminary requirementsfor management information systems in economic organizations",Information and Software Technology 49 (2007) 960-984

[4]. Swanson, E. B. (1974). Management information systems: appreciation and involvement.ManagementScience,21(2), 178-188.

[5]. Lucas, H. C. (1975). Performance and the use of an information system.Management Science,21(8), 908-919.

[6]. Alavi, M., \& Carlson, P. (1992). A review of MIS research and disciplinary development.Journal ofManagement Information Systems,8(4), 45-62

[7]. Hua, H., \& Herstein, J. (2003).Education management information system (EMIS): Integrated data and information systems and their implications in educational management. Paperpresented at the annual conference of comparative and International Education Society.

[8]. CGS (Pvt) Ltd, "Educational Institutions Management Information System", Corporate General Solutions, Management and Information Systems Consultants

[9]. Hemmi, A., Bayne, S., \& Land, R. (2009). The appropriation and repurposing of social technologies in higher education.Journal of Computer-Assisted Learning, 25(1), 19-30

[10]. Killion, J., \& Bellamy, T. G. (2000). On the job: Data analysts focus school improvement efforts.Journal of Staff Development, 21(1)

[11]. Bernhardt, V. L. (2004).Data analysis for continuous school improvement(2nd ed.). Larchmont, NY.

[12]. onald Yanosky (2009), 'Institutional Data Management In Higher Education”, Educause Center for Applied Research, EACR Key Findings

[13]. Suphan Nasir,'The development, change, and transformation ofManagement Information Systems (MIS): A contentanalysis of articles published in business and

[14]. Marketing journals “, International Journal of Information Management 25 (2005) 442-457

[15]. Marks A. Exploring universities' information systems securityawareness in a changing higher education environment:a comparative case study research. PhD thesis, University ofSalford; 2007.

[16]. Kerievsky B. Security and confidentiality in a university computernetwork. ACM SIGUCCS Newsletter Archive 1976;6(3):9-11

[17]. Ronald R. Ringing the alarm on campus computer security. BlackIssues in Higher Education 2001;18(20):50-1.

[18]. Barsanti C. Modern network complexity needs comprehensivesecurity. Security 1999;36(7):65-8.

[19]. Denning DE. Information warfare and security. USA: ACM Press; 1999.

[20]. Diffenbach, J. (1988). Expert systems could be a valuable new tool for enrollment management.Cause/Effect:College and University Systems Exchange,11(2), $22-26$.

[21]. Iyengar, J. V. (1997). An expert system for MBA admissions.Journal of Computer Information Systems,37(4),55.

[22]. Cassidy, D. T. (2005). Education Management Information System (EMIS) Development in Latin America and the Caribbean: Lessons and Challenges.

[23]. Gulsim Kadyrovna Sagitova (2012),'Management Information System for Higher Educational Institutions During Kazakhstan Transition to Knowledge Economy", World Applied Sciences Journal 18(Special Issue of Economics): 55-60

[24]. D.K.Allen and T.D.Wilson(1996), "Information Strategies in UK higher Education Institutions", International Journal of Information Management, Vol 16,No 4,pp 239-251

[25]. Fellow.V and T.D.Wilson (1993),"The management information requirements of heads of university departments", Journal of information sciences, 19(6), 425-438

[26]. Green, D. (1994). What is quality in higher education? Milton Keynes: The Society for Research into Higher Education/ Open iversity Press.

[27]. Batten, C., \& Trafford, V. (1985). Evaluation: An aid to institutional management. In G. Lockwood., \& J. Davies (Eds.), Universities: The management challenge. Guildford: SRHE \& NFER- Nelson.

[28]. Findlay, P. (1990). Developments in the performance indicator debate in the United Kingdom. In L.C.J. Goedegebuure, P.A.M. Maassen \& D.F. Westerheijden (Eds.), Peer review and performance indicators. Quality assessment in British and Dutch higher education. Utrecht: Lemma.

[29]. Levine, A.E. (1982). Quality in Baccalaureate program: What to look for when David Riesman can't visit. Educational Record, 63, 13-18.

[30]. Ross, K.N., \& Mtihlck, L. (1990). Planning the quality of education. The collection and use of data for informed decision-making. Oxford: Pergamum.

[31]. Frazer, M. (1994). Quality in higher education: An international perspective. In D. Green (Ed.), What is quality in higher education? Milton Keynes: The Society for Research into Higher Education/ Open University Press. 
[32]. J. Stallaert, Automated timetabling improves course scheduling at UCLA, Inter-faces 27 (1997) 67-81.

[33]. N. Chantal, D. de Werra, Extension of coloring models for scheduling purposes,European Journal of Operational Research 40 (1989) 32-37.

[34]. L. Foulds, D. Jonhson, SlotManager: a microcomputer-based decision support sys-tem for university timetabling, Decision Support Systems 27 (2000) 367-381:

[35]. Liang, C. Lee, E. Turban, Model management and solvers for decision support,Handbook on Decision Support Systems, Volume 1, Springer-Verlag, 2008,pp. 231-258.

[36]. Valeri Pougatchev, Ashok B.Kulkarni, "Technical aspects of the integrated management information system for educational institutions", International Journal of System Applications, Engineering \& Development, Issue 4,Volume 5,2011

[37]. Dr. V. D. Dudeja (2000),"Management Information Systems in The New Millennium, Challenges and Opportunities", ISBN 817169-06-6, Commonweath Publishers

[38]. European Association for Quality Assurance in Higher Education-EAQAHE-2005, p 20

[39]. Goodhue, D. L. (1997). The model underlying the measurement of the impacts of the IIC on theend-users.Journal of the American Society for Information Science,48(5), 449-453.

[40]. Davis, F. (1989). Perceived usefulness, perceived ease of use, and user acceptance of informationtechnology.MIS Quarterly,13(3), $319-340$.

[41]. Nur Naha Abu Mansor, Ananya Raka Chakraborty, Tay Ke Yin, Zeynep Mahitapoglu ,’Organizational Factors Influencing Performance Management System in Higher Educational Institution of South East Asia", The 2012 International Conference on Asia Pacific Business Innovation and Technology Management, Procedia - Social and Behavioral Sciences 40 (2012) $584-590$

[42]. Fondazione CRUI, Campus One. Guida alla valutazione dei corsi di studio [Guidelines to the evaluation of degree courses]. Roma: CRUI, 2003

[43]. Michalis Xenos, Thanos Papadopoulos, "Computer Aided Evaluation Of Higher Education Tutor's Performance", Studies in Educational Evaluation 33 (2007), 175-196

\section{Biodata}

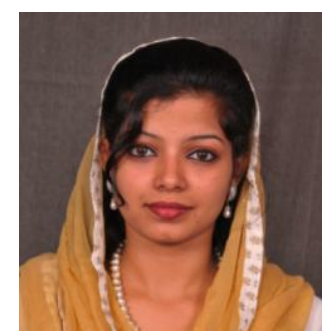

Rubina Ashmi

PhD Research ScholarMadurai Kamaraj University, Tamil Nadu,India

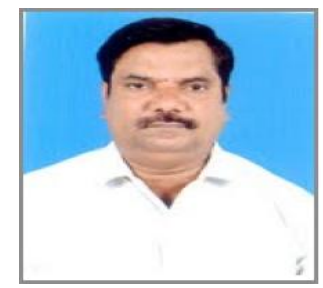

Dr.K.Ravichandran, MBA, PhD

Special Officer, Professor, Head of the Department of Entrepreneurship studies, Madurai Kamaraj University, Tamil Nadu, India 